\title{
UNIFORMIDADE DO CURRÍCULO ESCOLAR E AS DISPARIDADES DO CONTEXTO EDUCACIONAL
}

\author{
Jailma Maria Pimentel Barbosa ${ }^{\mathrm{I}}$ \\ "o currículo escolar assume-se como um instrumento \\ privilegiado de seleção escolar e não de sucesso \\ escolar, (...) o que condiciona a sua assimilação por \\ parte dos alunos oriundos de meios mais \\ desfavorecidos."
}

(MENDONÇA, 2009, p. 120).

RESUMO: É necessário discutir acerca da uniformidade do currículo escolar, sendo essencial na construção de uma educação mais plural em uma sociedade tão diversa quanto à brasileira. Tendo como objetivo analisar a relação da escola, os conteúdos e os saberes construídos historicamente. Foram realizadas pesquisas bibliográficas acerca das vantagens e desvantagens dessa uniformização mediante as disparidades do atual contexto educacional. Dos artigos consultados foi possível observar que o currículo tem sido um instrumento central do processo educativo de disseminação de identidades, diversidades culturais e construção de saberes. Os artigos permitiram constatar que é necessário reforçar a ideia de um currículo baseado na pluralidade, ou diversidade.

Palavras-chave: Currículo. Escola. Sistemas de ensino. Disparidades. Uniformidade.

\section{Considerações Iniciais}

Considerando a ideia de que a formação e organização escolar é um tanto "complexa" torna-se necessário o estudo e a compreensão do currículo como condição de extrema relevância para uma mudança de qualidade na escola atual. A

\footnotetext{
${ }^{1}$ Aluna do Ciclo de Seminários de Acesso ao Mestrado em Educação da Universidade da Madeira UMa (Portugal) - Turma Recife II.
} 
formação escolar sempre foi motivo de discussões acirradas entre pesquisadores da área educacional. Tais discussões derivam dos conteúdos escolares e sua funcionalidade na vida prática do aluno ao ingressar na sociedade. Questões como: o que necessariamente ensinar e quais conteúdos devem fazer parte do currículo escolar, suscitam debates no âmbito da educação. A escola tem uma cultura própria e é representada em um conjunto de práticas, valores e crenças, partilhados por todos aqueles que interagem no seu contexto. A sociedade por sua vez, espera da educação que seja proporcionada uma escola para todos de qualidade e que seja revisto as concepções da ação educacional. Dessa forma o presente trabalho pretende dissertar acerca da uniformidade do currículo escolar, argumentando a respeito das vantagens e desvantagens mediante as disparidades do atual contexto educacional, presente nas realidades vividas em uma sociedade tão diversa quanto à brasileira.

Em meio a tantas mudanças no cenário educacional brasileiro, são muitos os escritos sobre currículo e, especialmente, sobre o que necessariamente ensinar e quais conteúdos devem fazer parte do currículo escolar. No sistema educacional, o currículo tem sido um instrumento central de disseminação de identidades, diversidade cultural e construção de saberes público.

\section{UNIVERSALIZAÇÃO DO CURRÍCULO ESCOLAR}

$\mathrm{Na}$ escola brasileira, o currículo escolar ainda encontra-se relacionado a uma questão histórica. A história da educação no Brasil revela que a escola sempre serviu a um determinado grupo social que a dominava, tal fato derivava-se, portanto do mero processo histórico e civilizatório. Sendo razoável lembrar a "intencionalidade" das propostas curriculares das inúmeras situações históricas em que as sociedades modernas tenham passado. Sendo necessário ressaltar que tal discussão sempre foi travada por aqueles que defendiam uma orientação curricular quer humanista, quer científica. Pode-se dizer que desde o período de colonização portuguesa no Brasil, com os jesuítas e os procedimentos do Ratio Studiorum até a ditadura civil-militar do capital, com o movimento golpista de 1964 , houve profundas e sucessivas ações tanto na legislação e organização escolar quanto no currículo. 
Para Sanfelice (2008), “(...) O currículo escolar é sempre produto de um contexto histórico determinado que, intencionalmente, será alterado quando as conjunturas socioeconômicas se transformarem (...)." Deste modo, a presença das diferenças curriculares na educação brasileira, para cidadãos considerados iguais perante a lei, torna-se uma realidade desigual perante as realidades sócio-econômica e cultural subjacentes a nosso país. Muitas foram, às alterações curriculares feitas no transcorrer dos dois últimos governos dos dois últimos presidentes do Brasil. No entanto, diferenças profundas ainda continuam por acentuar-se no sistema educativo brasileiro, a grande separação entre a "educação para os pobres" e educação para os ricos”. Tal indagação, nada tem haver com democracia e justiça social.

Embora o significado do currículo escolar tenha grande repercussão no "bom" funcionamento do sistema escolar, sempre foi concebido como algo separado e desprovido de maiores iniciativas de melhoria para a instituição escolar, totalmente separado de significações mais profundas que contribuíssem em especial para o desenvolvimento das habilidades cognitivas e intelectuais dos alunos. O currículo era considerado pela tradição escolar como uma seriação de conteúdos escolares onde a estrutura era norteada pelas exigências de cada unidade escolar e características de cada instituição, sendo desenvolvido ao longo do ano letivo mediante a estruturada estabelecida pelo projeto político pedagógico da instituição.

A expressão "currículo" incorpora um significado próprio segundo o pensamento dos autores e orientações teóricas, no entanto, segundo Cool (200o, p. 44) “(...) O Currículo torna-se um instrumento que serve para orientar a prática pedagógica, é uma ajuda para o professor." Cool considera que há, enfim, a ideia de que a função do currículo atual não pode limitar-se a enunciar uma série de intenções, princípios e orientações gerais, assim, para o autor por estar excessivamente distante da realidade das salas de aula, tornando-se de escassa ou nula ajuda para os professores.

Os aspectos revelados sobre o currículo escolar anteriormente nos fazem pensar que ele é algo que pode modificar a prática educativa, Cool afirma, “(...) o Currículo escolar é uma ligação entre princípios gerais e sua tradução operacional, entre a teoria educacional e as práticas pedagógicas, (...) entre o que é prescrito e o que realmente 
sucede nas salas de aula" (COOL, 20oo, p. 45). No entender de Cool, é papel do currículo escolar evitar o distanciamento entre os dois extremos, ou seja; a teoria e prática educativa, servindo como instrumento para orientar a ação dos professores. Para o autor, torna-se papel do currículo escolar contemplar as aptidões dos alunos e os interesses das comunidades onde as escolas se inserem.

Vale enfatizar a problemática do currículo escolar em documentos oficiais, os quais revelam intencionalidade como é o caso da Constituição Federal Brasileira regulamenta e dirigi a vida em nosso país. Esta constituição refere:

A educação, direito de todos e dever do Estado e da família, deverá ser possibilitada ao educando com o envolvimento de segmentos da sociedade, no intuito de desenvolver o pleno desenvolvimento da pessoa, e sua formação para o exercício da cidadania e sua qualificação para o trabalho. (CFB, p. IIg).

Observando o artigo 206, e seu inciso III, percebe-se que o ensino pode ser ministrado com base em princípios do pluralismo, ideias e de concepções. A constituição defende o pluralismo de concepções pedagógicas, as quais devem ser manipuladas como recursos pedagógicos, que facilitem o processo de ensino e aprendizagem.

Da mesma maneira, os Parâmetros Curriculares Nacionais PCN's os quais foram formulados em dezembro de 1996, pelo Ministério da Educação - MEC, com o objetivo de direcionar e promover a preparação básica comum a todos os cidadãos, objetivando unificar os currículos escolares para que nenhum indivíduo tenha uma educação deficitária. A acepção de currículo que é apresentada pelos PCN's, permite uma organização onde o conhecimento é desenvolvido por áreas interligadas através de temas transversais.

Na sequência a Lei de Diretrizes e Bases da Educação Nacional - LDB, lei federal no 9394 / 1996, no título 4, art. 8, que permite às escolas flexibilidade para alcançar seus objetivos, pois, possibilita a autonomia organizacional de cada sistema de ensino. A LDB demonstra a preocupação e valorização das atividades extraescolares como componentes necessários para a composição de um bom currículo 
escolar. A parte diversificada seria então conteúdos específicos e inerentes às regiões brasileiras, à economia, à clientela.

Tais fatos leva-me, a refletir sobre a educação oferecida a população rural, assim, é preciso frisar que os movimentos populares propiciaram importantes conquistas para o campo educacional, dentre elas: A acessibilidade de todos os brasileiros à educação formal, garantida pela CFB de 1998, em seu art. 206, estabelece: "A igualdade de condições para o acesso e permanência na escola". Tal constituição além de garantir o compromisso do governo e da sociedade brasileira em promover a educação para todos, possibilita o direito, o respeito e à adequação da educação escolar às singularidades culturais e regionais. Muito embora esses preceitos tenham trazido à tona um novo contexto: o direito à educação da população do campo "no próprio campo" com qualidade.

As diferenças que se estabelecem nas relações entre o rural e urbano, tem preconizado no nosso País a defesa de políticas públicas para o desenvolvimento do campo, vinculada a educação escolar. Torna-se uma necessidade rever às diferenças culturais em seus muitos aspectos, as quais são bastante reais. Como consequência, proporciona-se aos povos do campo, uma educação baseada em um currículo substancialmente urbano que em geral é deslocado das urgentes necessidades e da realidade do campo.

Assim, afirma uma clara alusão ao modelo urbano. Inicialmente, tais políticas públicas, deverão ser construídas com as próprias pessoas dos direitos que as exigem, tratando-se de uma educação das pessoas do campo e não para as pessoas que lá vivem.

\section{VANTAGENS E DESVANTAGENS}

A escola atual tornou-se essencialmente universalista. Tal problemática nos leva a refletir sobre o currículo escolar na atualidade, leva-nos também a reconhecer a força do universalismo como um objeto regulador e motivador do ambiente escolar e denota um tanto de naturalização dos saberes obtidos na escola do ensino fundamental. 
Assim, Mendonça (2009) explica que a uniformidade do currículo pode conduzir o aluno ao insucesso escolar, pois as práticas educativas vivenciadas dentro deste contexto acentuam ainda mais as diferenças existentes com relação ao ritmo de aprendizagem e motivação. Segundo a autora, um ponto importante seria pensar em um currículo diversificado para cada contexto e realidade, que se leva em conta a pluralidade ou diversidade local, ou seja, como explica Leite (200o), "é necessário então que o currículo se estruture na idéia central da escola e dos professores, tendo como pressuposto a configuração escolar, se adequando ao espaço, ao tempo, a comunidade e ao mundo.” Assim, segundo Leite, será garantido ao aluno, bem como ao professor uma cidadania crítica baseada na adaptação de inovações pedagógicas.

Forquin (apud FRANCO, 1997), fala sobre a relação recíproca e complexa existente entre escola e cultura. Recíproca porque, como ele afirma, "a cultura é o conteúdo substancial da educação (...), a educação não é nada sem a cultura e sem ela tampouco pode mudar muita coisa. Mas, paralelamente, dir-se-à que é pela e na educação que a cultura se transmite e se perpetua". Por outro lado, para o autor, a complexidade da escola esta em selecionar elementos da cultura que irá transmitir. Assim, os conhecimentos culturais repassados pela escola, ou seja, a sabedoria coletiva de um povo que antecedem e ultrapassam o indivíduo, poderá não mais existir.

Como solução para a problemática abordada, surge à necessidade da reformulação do currículo escolar, tornando-se a tônica das angústias de todos aqueles que pensam a "Educação". Alguns pontos necessitam ser discutidos quando o assunto é a universalização do currículo escolar. A este propósito, Formosinho afirma que:

O "currículo uniforme pronto a vestir”, (“...) seja de "tamanho único" ou de tamanhos estandardizados", arrasta consigo uma pedagogia uniforme, que se traduz, nos mesmos conteúdos, a mesma extensão dos programas e limites estreitos para o ritmo de implementação, a grelha horária semanal uniforme, as cargas horária semanal uniforme, as cargas horárias determinadas por disciplina. (FORMOSINHO, MACHADO 2008, p. 8).

Aqueles que defendem a universalização do currículo argumentam que a escola transmite "saberes público", onde todos têm acesso, independentes das 
circunstâncias e dos interesses particulares. A base de todo o conhecimento é a cultura. A cultura é responsável pelo acesso aos conhecimentos e competências fundamentais.

Contudo, Segundo Mendonça:

(...) Os currículos iguais obrigam ao uso de iguais pedagogias e prevêem uniformidade nas exigências, nos resultados, nos comportamentos, na linguagem, no saber, na extensão dos programas, nos tempos de transmissão de conhecimentos e nos períodos de avaliação, (...) acabando por tornarem-se insensível às diferenças pessoais, não permitindo percursos escolares diferenciados. (MENDONÇA, 2009, p. II6, II7).

A possível existência de um currículo universal, enfatizado por Sacristán, (apud COUTO, 2002), onde não aparecem “(...) as aspirações, formas de pensamento, expressão e comportamentos dos diferentes grupos sociais da população da qual se nutre o sistema educacional”. Tal acepção imortaliza as formas de dominação existentes desde os primórdios da nossa civilização. Esquecendo-se das culturas locais, das riquezas regionais, criando um dualismo escolar - para elite, propõe-se uma educação mais intelectual; para os desprovidos de tantas regalias "como a população rural”, propõese uma educação mais corporal e emocional. A divergência das propostas curriculares além de restritiva é histórica para a educação: uma pedagogia intransigente que orienta currículos diversificados para cada classe social, sem considerar aspectos referentes à cultura das etnias, das realidades regionais, dos interesses dos alunos e das necessidades do mercado de trabalho.

Em contra partida, Forquin (1993) afirma que o currículo é substancialmente político, tornando-se a escolha curricular uma opção também política. A perspectiva que o autor nos apresenta é a que deixamos de relativizar uma das premissas mais presentes nas atuais propostas curriculares: "os conteúdos escolares devem estar estritamente relacionados aos interesses e necessidades de nossos alunos". (FORQUIN, I993, p. 154). Então, uma boa possibilidade para inserção da escola à realidade seria a formação de uma consciência crítica, onde o diálogo seja uma constante na troca educativa, baseado na ética, na dignidade do outro, na justiça, educando assim para a 
liberdade. Tal visão busca atingir os espaços da formação do professor, como capaz de transformar a prática educativa e pedagógica.

\section{Considerações Finais}

O estudo ora desenvolvido, possibilitou-me a compreensão da complexa discussão existente entre pontos basilares que conduzem o currículo escolar no nosso sistema de ensino, entre aquilo que é proposto e o que é feito, entre o que diz a legislação e o que acontece nas escolas de todo o país, observando-se o hiato entre o currículo praticado, as propostas curriculares e o que acontece nas salas de aula de todo o país. A sonegação de direitos básicos aos alunos menos favorecidos, muitas vezes não atendidos em necessidades básicas e específicas, a constituição de um processo educativo com uma linguagem única e comum para ricos e pobres tem sido a tônica de quem prega uma educação de qualidade para todos.

A realidade campesina, na qual convivo diariamente, sofre impetuosamente com a submissão a um currículo totalmente formulado para o trabalho na escola urbana. Com efeito, os alunos que ali se encontram possuem histórias de vidas diferentes, mundos diferentes, pretensões diferentes e limitações parecidas com todo alunado da rede pública de ensino. No entanto, as suas carências e dificuldades não são trabalhadas haja vista, as limitações e fragilidades que o próprio campo impõe a escola rural. É preciso que seja observado o que diz a legislação educacional para a educação do campo, tornando o currículo adequado as singularidades da vida no campo, influenciando positivamente no desempenho acadêmico de seus alunos.

A partir da análise feita em alguns documentos oficiais observa-se, que é possível sim, promover ações que contemple a diversidade, sem deixar de observar a aprendizagem dos alunos. As prioridades do currículo escolar devem contemplar o trabalho com a diversidade.

Para tanto, conclui-se então que é necessário contestar o currículo culturalmente dominante, que não observam as peculiaridades e as nuances de nosso sistema educativo, na perspectiva de compreender como se dá esse processo, até mesmo apontar caminhos, para uma educação de qualidade. $\mathrm{O}$ reconhecimento da 
educação como um direito cultural, nos faz pensar que “(...) o currículo escolar deve ser discutido e formulado de maneira flexível, que permita as diferenças culturais sem renunciar à universalidade de muitos traços culturais e de certos objetivos” (Pacheco, p. 30 ).

Neste cenário, almeja-se a necessidade de reforçar a ideia de um currículo baseado na pluralidade, ou diversidade, que proporcione aspectos de aprendizagem, promova a cidadania daqueles que ocupam o espaço educativo. A Universalização do currículo em nada tem haver com a unicidade do ensino, tem sim haver com os valores, critérios e saberes de cada um. Assim, é necessário refletir até que ponto o universalização do currículo pode contribuir para a aprendizagem sem que isso deixe lacunas referentes à autonomia cultural e social de cada espaço escolar, sem que isso faça do ensino e da aprendizagem um instrumento hegemônico de poder.

\section{REFERÊRENCIAS BIBLIOGRÁFICAS}

BRASIL. Constituição. República. Federativa do Brasil, Ministério Da Educação, 1988.

. LDB, Lei 9394/96 Lei de Diretrizes e Bases da Educação Nacional. Brasília: Corde, 1996.

- Ministério da Educação. Diretrizes Operacionais Para Educação Básica das Escolas do Campo. CNE/MEC, Brasília, 2002.

Parâmetros Curriculares Nacional de $\mathrm{I}^{\underline{a}}$ a $4^{\underline{a}}$ série do Ensino Fundamental. Ministério da Educação. Secretaria de Educação Fundamental. 3. Ed. Brasília, 20or.

COOL. César, Psicologia e Currículo, 5ª edição, São Paulo: Editora Ática, 2000.

- Estrutura Grupal, Interacción entre Alunnos y Aprendizáge Escolar. Infancia y aprendizage, $27-8$, p.II9 - 38, 1984 .

FORMOSINHO, João. MACHADO Joaquim. Currículo e Organização: as equipas educativas como modelo de organização pedagógica. Universidade do Minho Portugal. Currículo sem fronteiras, p. 5-16. 2008.

FORQUIN, Jean-Claude. Escola e Cultura: as bases sociais e epistemológicas do conhecimento escolar. Porto Alegre: Artes Médicas, 1993. 
MENDONÇA, Alice. O Insucesso Escolar: Políticas Educativas e Práticas Sociais. Um estudo de caso sobre o Arquipélago da Madeira. Portugal: Edições Pedago, Lda, 2009.

MOREIRA, A. F. e SILVA, T. T. da. Sociologia e teoria crítica do currículo: uma introdução. In: (Orgs). Currículo, cultura e sociedade. São Paulo: Cortez, 1995.

. Currículos e Programas no Brasil. São Paulo: Papirus, 2006.

SACRISTÁN, J. Gimeno. O Currículo: os conteúdos do ensino ou uma análise prática. In: SACRISTÁN, J. Gimeno; Pérez Gómez, A. I. Compreender e Transformar o ensino. Porto Alegre: Artmed, 2000.

.. A cultura para os sujeitos ou os sujeitos para a cultura? O Mapa Mutante dos Conteúdos na Escolaridade. In: poderes instáveis em educação. Porto Alegre: Artmed.

SANTOMÉ, Jurjo Torres. As Culturas Negadas e Silenciadas no Currículo. In: SILVA, Tomaz Tadeu da (org). Alienígenas na Sala de Aula: uma introdução aos estudos culturais em educação. Petrópolis: Vozes, 1995.

SILVA. T. T. Documentos de Identidade: Uma introdução às teorias do currículo. Autêntica: Belo Horizonte, 20oI.

(Orgs.) Currículo, cultura e sociedade. São Paulo: Cortez (1994), 6ª ed. 2002, p. 7-37.

\section{OUTRAS REFERÊNCIAS}

BRASIL. LDB, Lei n ${ }^{\circ}$ 9394/96 - Lei de Diretrizes e Bases da Educação Nacional. Capítulo II - Educação Básica. Disponível em www.adusp.org.br/arquivo/LDB?CapIILDB.htm>, acesso em: 20 agosto 201 .

COUTO, Regina Célia do. Práticas Pedagógicas, ensino de história e multiculturalismo: uma perspectiva de currículo, disponível em <www.ichs.ufop.br/perspectivas/anais/GTo507.htm>, acesso em: 2I fev 201 .

DIEB, Dicionário Interativo da Educação Brasileira. Currículo Escolar. Disponível em www.educabrasil.com.br/eb/dic/dicionario.asp?id=72, acesso em II fev 2011 .

FINO, Carlos Nogueira; SOUSA, Jesus Maria. Alterar o Currículo: mudar a realidade. Disponível em <www3.uma.PT/Carlos fino/publicações/r9.pdf>, acesso em: 2I mar 20II. 
FINS. Documento Introdutório. Versão de agosto / 1996, disponível em <HTTP: www.zinder.com.br/legislacao/pcn.fund.htm>. Acesso em: i3 nov 2010.

FRANCO, Aléxia Pádua. Forquin - escola e cultura, disponível em <www.seer.ufu.br/index.php/educacaofilosofia/article/download/903/818>, acesso em: mar, 20II.

GOMES, Ângela de Castro Correia. O currículo como instrumento central do processo educativo: uma reflexão etimológica e conceitual, disponível em 〈www.pucpr.b/eventos/educere/educere2009/.../2925_1387.pdf $\rangle$, acesso em: or mar 2011.

GONÇALVES, Roseli. (Re) pensar o Currículo Escolar na Epistemologia Educacional, disponível em <www.artigos.netsaber.com.br/.../artigo $\rangle$, acesso em: ıo mares 20II.

LEITE, Carl inda. Uma Análise da Dimensão Multicultural no Currículo. Revista da Educação, 2000. Disponível em <www.fpce.up.pt/ciie/publs/artigos/AnalRevEducacao.doc〉, acesso em: 27 fev 201 I.

MESQUITA, Adriano de. A Formação do Currículo Escolar nas Séries Iniciais. Disponível em www.webartigos.com/articles/13479/r, acesso em: 28 agosto 2011. 